A new feature of the book is an admirable summary of the place of radiotherapy in general surgery and one feels equal space should have been devoted to present-day treatment of fluid and electrolyte balance.

The presentation and printing of this book is both spacious and distinct and it remains a sound counsel which few would not be wiser for reading.

\section{CEREBRAL LIPIDOSES A Symposium}

Edited by L. van Bogaert, M.D., J. N. Cumings, M.D., F.R.C.P. and A. Lowenthal, M.D. Pp. $\mathbf{x}+212$ pages, illustrated. Oxford: Blackwell Scientific Publications. 1957. 42s.

This book is a collection of 20 papers read at a Symposium on Cerebral Lipidoses in Antwerp in 1955. The papers deal with histological, histochemical and chemical aspects of the various lipidoses, and all are of a very high standard providing a really up to date picture of this interesting group of diseases. The various chapters are followed by short discussions which frequently help to clarify controversial points. The illustrations, both in colour and black and white, are good and the editors have done a fine job in producing such a coherent work.

\section{THE BRITISH ENCYCLOPAEDIA OF MEDICAL PRACTICE PHARMACOPOEIA}

Second edition. Pp. viii $+696+$ index 32 . London: Butterworth \& Co. Ltd. I957. 65 s.

There is an ever increasing and more bewildering array of proprietary medicines as activity grows in the pharmacological field. Any book, therefore, which attempts to list and describe the more important preparations must be helpful not only to the General Practitioner but also to libraries and to Pharmacology Departments in Medical Schools. This book lists some 1,400 preparations in alphabetical order and gives details of their composition, action, indications, dosage, and packaging. It also describes their relationship, if any, to the Pharmacy and Poisons Act or the Dangerous Drugs Act, and indicates whether or not the preparation is officially described in the B.P. or the B.P.C. There is a useful appendix giving the names and addresses of all the important pharmaceutical firms at home and abroad, and another listing discontinued products. As the subject matter of the book is arranged alphabetically, an index in the ordinary sense of the work is not essential, but an index of conditions is provided with a list of the proprietary medicines used in their treatment. The publishers note that a selection has been made from thousands of preparations submitted for consideration, they further state that there is no intention to advise which drugs should be used. This policy is probably the correct one for such a work, but it would perhaps have been useful to have given some indication of the criteris involved in the selection.

P.A.N. 용

PERIPHERAL NERVE REGENERATION

A Follow-up Study of 3,656 World War Injuries

Veterans Administration Medical Monograp $\frac{\pi}{9}$ Edited by BARNES Woodhall, M.D. and GILbERT W. BeEbe, Ph.D. Pp. xxiv + 671, with 6 ๑ illustrations. Washington D.C.: U.S. Govern ment Printing Office. 1957.

This comprehensive study of peripheral nerve regeneration is the result of a great programme of clinical research begun in America during the Second World War, and brought to fruition after the War by the National Research Council i. co-operation with the Veterans' Administration?

In the first two chapters the methods of sampling: assessment and statistical processing are described and a detailed account is given of the materiat studied and of the methods of treatment used. The next section deals in detail with the recovery of motor function and with the effect of the numerous factors influencing it. Subsidiary to this chaptes is the next, which is concerned with electrieat evidence of regeneration. A detailed considerat of sensory recovery and of the significance of factors acting on it is followed by a valuable sector on Pain and related phenomena. Followi chapters on autonomic and functional recoverys and on special aspects of the subject, a final section deals with the implications of what has gone before for the management of nerve injuries in the future

The Editors and the Heads of the five follow-up Centres are very much to be congratulated on the manner in which they have handled and sifted the enormous mass of detailed information available tơ them. The evidence arising from this study now. enables definite answers to be given to many of the basic problems of nerve repair. For instance, i appears that delay in definitive suture involves variable loss in the final level of motor recovery. averaging about I per cent. of maximal performancé for every six days of delay. It is interesting to compare these findings with the results of recent English work in the same field. Evidence of statistical significance is presented on many othen questions of importance to the surgeon. The chapter on Pain by Drs. White and Selverstone is notable for its excellent description of the causalgie syndrome and for its clear separation of otherv painful phenomena from causalgia.

The final chapter, based on the results of this painstaking survey, constitutes by itself a small but valuable guide for the surgeon who already hase some knowledge of these problems. It is this section which is chiefly valuable to the post-graduate? student, for the book as a whole contains so much information as to make it required reading for a very? 